\title{
Treatment success and mortality among adults with tuberculosis in rural eastern Uganda: a retrospective cohort study
}

\author{
Jonathan Izudi, Imelda K. Tamwesigire and Francis Bajunirwe
}

\begin{abstract}
Background: Successful treatment of tuberculosis leads to clinical and public health benefits such as reduction in transmission, complications, and mortality among patients. However, data are limited on treatment outcomes and the associated factors among persons with bacteriologically confirmed pulmonary (BC-PTB) in rural areas of high dual tuberculosis and Human Immunodeficiency Virus (HIV) burden countries such as Uganda. We investigated factors associated with successful treatment of tuberculosis and mortality among adult persons with BC-PTB in rural eastern Uganda.
\end{abstract}

Methods: We constructed a retrospective cohort of persons with BC-PTB from a routine tuberculosis clinic database in eastern Uganda. We performed bivariate and multivariate analysis. Using a 5\% level of significance, we ran a modified Poisson regression analysis to determine factors independently associated with treatment success and mortality rates.

Results: We retrieved 1123 records for persons with BC-PTB and the treatment outcomes were distributed as follows: $477(42.5 \%)$ cured, 323 (28.0\%) treatment completed, 17(1.5\%) treatment failed, 81(7.2\%) died, 89(7.9\%) lost to follow-up, and 136(12.1\%) not evaluated. Overall, 800 (81.1\%) of the 987 persons with BC-PTB that had treatment outcome, were successfully treated. Successful treatment of tuberculosis was less likely to occur among those with HIV infection (Adjusted risk ratio (aRR), 0.88; 95\% Confidence Interval (CI), 0.82-0.95), older than 50 years (aRR, 0.89; $95 \% \mathrm{Cl}, 0.81-0.97$ ), or male sex (aRR, 0.92; 95\% Cl, 0.87-0.98). Mortality was associated with HIV infection (aRR, 4.48; $95 \% \mathrm{Cl}, 2.95-6.79)$, older than 50 years (aRR, 2.93; 95\% Cl, 1.74-4.92), year of enrollment into treatment after 2015 (aRR, 0.80; 95\% Cl, 0.66-0.97), and Community-Based Directly Observed Therapy Short Course (aRR, 0.26; 95\% Cl, 0.13-0.50).

Conclusions: Treatment success rate among adult persons with BC-PTB in rural eastern Uganda is suboptimal and mortality rate is high. HIV infection and older age reduce chances of treatment success, and increase mortality rate. Older and HIV infected persons with BC-PTB will require special consideration to optimize treatment success rate and reduce mortality rate.

Keywords: HIV, Mortality, Treatment success rate, Tuberculosis, Uganda

\footnotetext{
* Correspondence: jonahzd@gmail.com

Department of Community Health, Faculty of Medicine, Mbarara University

of Science and Technology, P.O. Box, 1410, Mbarara, Uganda
}

(c) The Author(s). 2020 Open Access This article is licensed under a Creative Commons Attribution 4.0 International License, which permits use, sharing, adaptation, distribution and reproduction in any medium or format, as long as you give appropriate credit to the original author(s) and the source, provide a link to the Creative Commons licence, and indicate if changes were made. The images or other third party material in this article are included in the article's Creative Commons licence, unless indicated otherwise in a credit line to the material. If material is not included in the article's Creative Commons licence and your intended use is not permitted by statutory regulation or exceeds the permitted use, you will need to obtain permission directly from the copyright holder. To view a copy of this licence, visit http://creativecommons.org/licenses/by/4.0/. The Creative Commons Public Domain Dedication waiver (http://creativecommons.org/publicdomain/zero/1.0/) applies to the data made available in this article, unless otherwise stated in a credit line to the data. 


\section{Background}

Although tuberculosis is treatable and curable with a standard course of antibiotics, the disease continues to claim millions of lives globally. The 2019 World Health Organization (WHO) Global Tuberculosis report indicates that 10 million people developed tuberculosis disease in 2018 and 1.5 million of them died [1]. The WHO recommends that a good performing tuberculosis program should achieve at least 90\% treatment success rate and $85 \%$ cure rate [2]. These targets contribute to the effective reduction of tuberculosis transmission at household and community levels, and in reducing tuberculosis related complications and mortality [3]. Nonetheless, tuberculosis control programs all over the world have challenges in meeting the recommended treatment success rate particularly for persons with new bacteriologically confirmed pulmonary tuberculosis (BC-PTB) diagnosis. According to current data, global treatment success rate for persons with new BC-PTB diagnosis improved from $82 \%$ in 2016 [4] to $85 \%$ in 2017 [1], which is still lower than the desired target of at least $90 \%$.

Sub Saharan Africa has the highest burden of tuberculosis and the slowest decline in the number of tuberculosis incident cases [5], and suboptimal tuberculosis treatment success rate. Recent systematic review and meta-analysis show a treatment success rate of $76.2 \%$ among persons with BC-PTB in sub Saharan Africa over the past 10 years [6], far below the global treatment success rate of $85 \%$ [1] and the WHO recommended rate of at least 90\% [2]. This meta-analysis also shows that sub Saharan Africa may be experiencing a gradual but steady decline in tuberculosis treatment success rate [6]. There is therefore a need to conduct research that can inform interventions to improve treatment success rate particularly in sub Saharan Africa where the burden of tuberculosis and HIV are both very high. The burden of tuberculosis is higher among people living with Human Immunodeficiency Virus (PLHIV) where it is the number one cause of mortality [7]. Accordingly, more data are needed especially from rural or remote areas on treatment outcomes among persons with tuberculosis to inform interventions.

Therefore, the purpose of this study was to measure treatment outcomes, namely treatment success and mortality rates, among persons with BC-PTB in rural eastern Uganda, determine whether HIV infection is associated with these treatment outcomes, and identify other factors amenable to interventions that can contribute to treatment success rate.

\section{Methods}

\section{Study design}

We retrieved and reviewed records for adult persons with $\mathrm{BC}-\mathrm{PTB}$, persons with a biological specimen that is positive for Mycobacterium tuberculosis (MTB) on smear microscopy, culture, or molecular test like GeneXpert. We considered the 10 largest tuberculosis diagnostic and treatment units in the districts of Soroti, Kumi, Ngora, and Serere, all in eastern Uganda for data review and retrieval. The records are routinely collected by the TB clinics for use in reporting case load, tracking patient outcomes and form part of the National TB and Leprosy program surveillance. The records capture demographics, laboratory and clinical outcomes.

\section{Variables and measurements}

The independent variables included the following: district where the tuberculosis patient received treatment, level and location of health facility, health facility ownership type, year of tuberculosis treatment initiation, sex, age category, type of tuberculosis patient (new or previously treated), transfer-in status, baseline MTB load, type of drug regimen, HIV sero-status, type of Directly Observed Therapy Short Course (DOTS), availability of a treatment supporter, and patient residence. The treatment outcome data included: cured, treatment completed, treatment failed, lost to follow-up, died, transferred out, treatment success, and not evaluated.

All participants classified as lost to follow-up were verified by the TB focal persons of respective study sites using either the district TB unit or HIV register, while those reported as dead were confirmed by home visits and presentation of death certificates by either a treatment supporter, Community Health Worker, or family member.

The primary outcome of the analysis was treatment success rate and the secondary was mortality rate, both defined according to the WHO criteria [8]. We computed treatment success rate as the percentage of adult BC-PTB cases registered under DOTS in a given year who completed tuberculosis treatment with bacteriologic evidence of success (cured) or not cured but had completed treatment. Mortality rate was computed as the percentage of adult persons with BC-PTB who died from any cause during tuberculosis treatment.

\section{Inclusion and exclusion criteria}

We included all adult (15 years and older) persons with BC-PTB, diagnosed and treated between January 2015 and June 2018. The participants were either persons with new BC-PTB diagnosis or previously treated persons with BC-PTB, and if they were transferred-in, this should not have happened after 2 months of treatment at the preceding health facilities. Participants in this retrospective cohort were followed from the time of treatment initiation to treatment completion, with an average follow-up of 6 to 8 months. This study excluded participants with no treatment outcome evaluation 
namely those who were transferred out to other health facilities and those whose treatment outcome was unknown to the reporting TB unit.

\section{Data analysis}

In univariate analysis, we computed frequencies and percentages for categorical variables, and means with standard deviations for numerical data. In the bivariate analysis, we assessed differences in observed and expected frequencies in categorical variables between participants with successful versus non-successful tuberculosis treatment, and between persons with BC-PTB who died versus those who survived using the Chisquared test for expected cell counts above five, or the Fisher's exact test for expected cell counts less than five. For numeric data, we used Student's t-test to assess differences in their means. We performed sensitivity analysis to examine the effect of excluding persons with BCPTB diagnosed by GeneXpert since they did not have bacilli load data.

We used modified Poisson regression analysis with robust standard errors to perform multivariate analysis for all statistically significant variables identified at the bivariate analysis and reported the results as risk ratios (RR). The RR was a better measure of effect over the odds ratio (OR) for two reasons: 1) Our outcome variables had prevalence greater than $10 \%$, which we considered as a frequent outcome, the OR overestimates the degree of association compared to the RR; 2) When an outcome is rare (less than 10\%), both RR and OR estimates are comparable [9]. Since one of the outcome was large and another was less frequent, the RR provides an unbiased measure of effect and ensures harmonized reporting. We reported each RR with the corresponding 95\% confidence interval (CI), for both the unadjusted and adjusted results. The data analysis was performed in $\mathrm{R}$ programing language and statistical software version $3.5 .2[10]$ at the $5 \%$ level of significance.

\section{Human subjects' issues and ethics approval}

This study was reviewed and approved by Mbarara University of Science and Technology Research Ethics Committee (Reference number 03/11-18), and the Uganda National Council for Science and Technology (Reference number HS 2531). The need for patient consent was waived by the ethics committee because data collection involved retrieval of records from large numbers of persons with BC-PTB, for whom it would have been logistically impractical to reach and seek individual consent. Data were handled confidentially and anonymized by excluding personal identifiers namely names and locations at the time of data abstraction.

\section{Results}

Study profile of persons with BC-PTB in eastern Uganda Of 3025 persons with TB treated between January 2015 and June 2018 shown in Fig. 1, we excluded with reasons: 1) 1881 persons without BC-PTB of whom 1636 were persons with clinically diagnosed $\mathrm{TB}$ and 245 were persons with extra-pulmonary $\mathrm{TB}$; 2) 14 persons with $\mathrm{BC}$-PTB because they were below 15 years of age, and; 3) seven persons with BC-PTB because they had multidrug resistant TB. We therefore retrieved records for 1123 adult persons with BC-PTB and further excluded 136 persons with BC-PTB with no treatment outcome evaluation either because they were transferred to another health facility or their treatment outcome was unknown to the reporting health facility at the time of data abstraction. Therefore, our subsequent analyses included 987 records for adult persons with BC-PTB.

\section{Characteristics of participants with successful treatment outcome in eastern Uganda}

We presented and compared the characteristics of participants with and without treatment success and the results are shown in Table 1. Participants who were successfully treated were on average younger than those

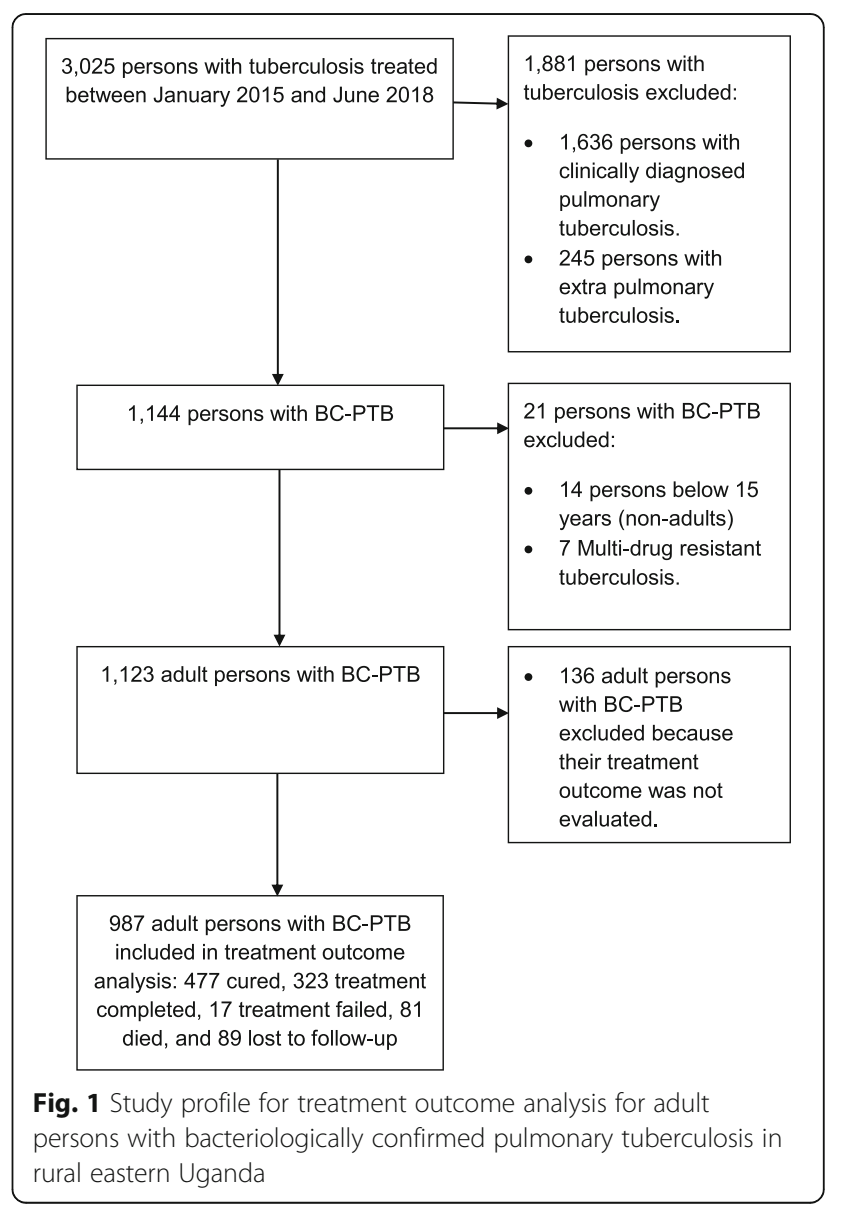


Table 1 Baseline characteristics of successfully and unsuccessfully treated participants

\begin{tabular}{|c|c|c|c|c|}
\hline \multirow[t]{2}{*}{ Characteristics } & \multirow[t]{2}{*}{ Level } & \multicolumn{2}{|c|}{ Tuberculosis treatment outcome } & \multirow[t]{2}{*}{$\boldsymbol{P}$-value } \\
\hline & & $\begin{array}{l}\text { Unsuccessful } \\
\text { (No. (\%)) }\end{array}$ & $\begin{array}{l}\text { Successful } \\
\text { (No. (\%)) }\end{array}$ & \\
\hline All participants & & $187(18.9)$ & $800(81.1)$ & \\
\hline \multirow[t]{4}{*}{ District } & Soroti & $104(55.6)$ & $359(44.9)$ & $<0.001$ \\
\hline & Kumi & $49(26.2)$ & $179(22.4)$ & \\
\hline & Ngora & $26(13.9)$ & $115(14.4)$ & \\
\hline & Serere & $8(4.3)$ & $147(18.4)$ & \\
\hline \multirow[t]{3}{*}{ Level of health facility } & Health Center IV & $67(35.8)$ & $341(42.6)$ & 0.221 \\
\hline & General Hospital & $40(21.4)$ & $161(20.1)$ & \\
\hline & Referral Hospital & $80(42.8)$ & $298(37.2)$ & \\
\hline \multirow[t]{2}{*}{ Location of health facility } & Rural & $45(24.1)$ & $230(28.7)$ & 0.232 \\
\hline & Urban & $142(75.9)$ & $570(71.2)$ & \\
\hline \multirow[t]{2}{*}{ Type of health facility ownership } & Public & $173(92.5)$ & $707(88.4)$ & 0.132 \\
\hline & Private not-for-profit & $14(7.5)$ & $93(11.6)$ & \\
\hline \multirow[t]{4}{*}{ Year of tuberculosis treatment } & 2015 & $69(36.9)$ & $298(37.2)$ & 0.322 \\
\hline & 2016 & $45(24.1)$ & $172(21.5)$ & \\
\hline & 2017 & $47(25.1)$ & $176(22.0)$ & \\
\hline & 2018 & $26(13.9)$ & $154(19.2)$ & \\
\hline \multirow[t]{2}{*}{ Sex } & Female & $46(24.6)$ & $290(36.2)$ & 0.003 \\
\hline & Male & $141(75.4)$ & $510(63.7)$ & \\
\hline \multirow[t]{3}{*}{ Age category } & $15-34$ & $73(39.0)$ & $387(48.4)$ & 0.037 \\
\hline & $35-50$ & $66(35.3)$ & $262(32.8)$ & \\
\hline & More than 50 & $48(25.7)$ & $151(18.9)$ & \\
\hline Age (mean (SD)) & & $41.20(15.70)$ & $37.89(15.15)$ & 0.008 \\
\hline \multirow[t]{2}{*}{ Type of patient } & New & $154(82.4)$ & $708(88.5)$ & 0.031 \\
\hline & Previously treated & $33(17.6)$ & $92(11.5)$ & \\
\hline \multirow[t]{4}{*}{ Pre-therapy MTB load } & $1+$ & $25(13.4)$ & $117(14.6)$ & 0.634 \\
\hline & $2+$ & $43(23.0)$ & $215(26.9)$ & \\
\hline & $3+$ & $64(34.2)$ & $251(31.4)$ & \\
\hline & Diagnosis by GeneXpert & $55(29.4)$ & $217(27.1)$ & \\
\hline \multirow[t]{3}{*}{ Drug regimen } & 2RHZE/4RH & $105(56.1)$ & $496(62.0)$ & 0.172 \\
\hline & 2RHZE/6HE & $63(33.7)$ & $250(31.2)$ & \\
\hline & 2RHZES/1RHZE/5RHE & 19 (10.2) & $54(6.8)$ & \\
\hline \multirow[t]{2}{*}{ HIV status } & Negative & $113(60.4)$ & $591(73.9)$ & $<0.001$ \\
\hline & Positive & 74 (39.6) & $209(26.1)$ & \\
\hline \multirow[t]{2}{*}{ Type of Directly Observed Therapy Short Course } & Health facility & $12(6.4)$ & $33(4.1)$ & 0.247 \\
\hline & Community & $175(93.6)$ & $767(95.9)$ & \\
\hline \multirow[t]{2}{*}{ Treatment supporter availability } & No & $24(12.8)$ & $98(12.2)$ & 0.924 \\
\hline & Yes & $163(87.2)$ & $702(87.8)$ & \\
\hline \multirow[t]{2}{*}{ Living in the same sub-county as that of the health facility } & Yes & $60(39.5)$ & $312(45.4)$ & 0.214 \\
\hline & No & $92(60.5)$ & $375(54.6)$ & \\
\hline
\end{tabular}

Note: 1) 2RHZE/4RH: 2 months of Rifampicin (R), Isoniazid (H), Pyrazinamide (Z),Ethambutol / 4 months of RH; 2) 2RHZE/6EH: 2 months of RHZE)/ 6 months of EH; 3 ) 2RHZES/IRHZE/5RHE: 2 months of RHZE, Streptomycin/One month of RHZE/ 5 months of RHE; 4) MTB: Mycobacterium tuberculosis 
who were unsuccessfully treated: $37.89 \quad(\mathrm{SD}=15.15)$ years versus $41.20(\mathrm{SD}=15.70), p=0.008$. Most of the successfully treated participants were males (510 $(63.7 \%))$, aged 15 to 34 years (387 (48.4\%)), and persons with new BC-PTB diagnosis $(708(88.5 \%))$. Other participant characteristics namely sex, age, and HIV status differed between those successful treated and those unsuccessfully treated.

There was no difference in treatment success rate with respect to health facility attributes (level, location, and ownership type), year of treatment, drug regimen and baseline bacilli. Sensitivity analysis results showed that the exclusion of persons with BC-PTB diagnosed by GeneXpert resulted in no change in proportions of treatment success (Chi-square test, $p$ value changed from 0.634 to 0.511$)$.

\section{Distribution of treatment outcomes among persons with BC-PTB in eastern Uganda}

In Table 2, the treatment outcomes for the 1123 records were as follows: $477(42.5 \%)$ cured, $323(28.8 \%)$ treatment completed, 17 (1.5\%) treatment failed, 81 (7.2\%) died, 89 (7.9\%) lost to follow-up, and 136 (12.1\%) not evaluated. Table 2 also shows the treatment outcomes stratified by district of assessment. After excluding not evaluated participants, revised analysis showed that 800 (81.1\%) persons with BC-PTB were successfully treated.

Factors associated with treatment success among persons with BC-PTB in eastern Uganda

Table 3 is a summary of results at unadjusted and adjusted analyses. In unadjusted analysis, participants from Serere district had increased treatment success rate compared to those from Soroti district (RR, 1.22; 95\% CI, 1.15-1.30). However, treatment success rate was lower among males compared to females (RR, 0.91; 95\%
CI, 0.86-0.96), those more than 50 years of age than 15 to 34 years of age (RR, $0.88 ; 95 \% \mathrm{CI}, 0.81-0.97$ ), previously treated persons with $\mathrm{BC}-\mathrm{PTB}$ compared to persons with new BC-PTB diagnosis (RR, 0.90; 95\% CI, 0.80-1.00), and HIV infected than HIV non-infected (RR, 0.88; 95\% CI, 0.81-0.95). When we adjusted for all statistically significant factors, treatment success was less likely to occur among males (aRR, 0.92; 95\% CI, 0.87$0.98)$, patients older than 50 years of age ( $\mathrm{aRR}, 0.89 ; 95 \%$ CI, 0.81-0.97), those HIV infected (aRR, 0.88; $95 \% \mathrm{CI}$, $0.82-0.95)$ but more among residents from Serere compared to Soroti district (aRR, 1.22; 1.14-1.30).

\section{Baseline characteristics of persons with BC-PTB by survival status in eastern Uganda}

Table 4 shows the distribution of participant characteristics stratified by survival, namely alive or died. Of 987 participants whose treatment outcomes were evaluated, 81 (8.2\%) died. Most of the deaths were at referral hospital level (40/ 81 or $49.4 \%$ ) and in 2015 (35/81 or $43.2 \%)$. Participants who died were on average older than those who were alive: $44.80 \pm 16.82$ versus $37.95 \pm 15.05$ years, $p<0.001$. There was a statistically significant difference in mortality rate based on the district where treatment was received, level of health facility, year of tuberculosis treatment, participants' age, participant HIV sero-status, baseline bacilli, and form of DOTS. In sensitivity analysis, we found the exclusion of persons with BC-PTB diagnosed by GeneXpert resulted in no change in proportions of mortality (Chi-square test, $p$ value changed from 0.948 to 0.887 ).

\section{Factors associated with mortality among persons with BC-PTB in eastern Uganda}

Table 5 presents results for factors associated with mortality rate. In the unadjusted analysis, mortality rate was lower among participants who received treatment under

Table 2 Study profile and tuberculosis treatment outcomes by district in eastern Uganda

\begin{tabular}{|c|c|c|c|c|c|}
\hline Characteristics & $\begin{array}{l}\text { Soroti } \\
n=541\end{array}$ & $\begin{array}{l}\text { Kumi } \\
n=279\end{array}$ & $\begin{array}{l}\text { Ngora } \\
n=148\end{array}$ & $\begin{array}{l}\text { Serere } \\
n=155\end{array}$ & $\begin{array}{l}\text { Total } \\
n=1123\end{array}$ \\
\hline Treatment outcomes $(n=1123)$ & n (\%) & n (\%) & n (\%) & n (\%) & n (\%) \\
\hline Cure & $247(45.7)$ & $122(43.7)$ & $31(20.9)$ & $77(49.7)$ & $477(42.5)$ \\
\hline Treatment completed & $112(20.7)$ & $57(20.4)$ & $84(56.8)$ & $70(45.2)$ & $323(28.8)$ \\
\hline Treatment failed & $10(1.8)$ & $6(2.2)$ & $0(0.0)$ & $1(0.6)$ & $17(1.5)$ \\
\hline Died & $45(8.3)$ & $15(5.4)$ & $16(10.8)$ & $5(3.2)$ & $81(7.2)$ \\
\hline Lost to follow-up & $49(9.1)$ & $28(10.0)$ & $10(6.8)$ & $2(1.3)$ & $89(7.9)$ \\
\hline Not evaluated & $78(14.4)$ & $51(18.3)$ & $7(4.7)$ & $0(0.0)$ & $136(12.1)$ \\
\hline Tuberculosis treatment outcome available $(n=987)$ & $\begin{array}{l}\text { Soroti } \\
n=463\end{array}$ & $\begin{array}{l}\text { Kumi } \\
n=228\end{array}$ & $\begin{array}{l}\text { Ngora } \\
n=141\end{array}$ & $\begin{array}{l}\text { Serere } \\
n=155\end{array}$ & $\begin{array}{l}\text { Total } \\
\mathrm{n}=\mathbf{9 8 7}\end{array}$ \\
\hline Unsuccessful & $104(22.5)$ & $49(21.5)$ & $26(18.4)$ & $8(5.2)$ & $187(18.9)$ \\
\hline Successful & $359(77.5)$ & $179(78.5)$ & $115(81.6)$ & $147(94.8)$ & $800(81.1)$ \\
\hline
\end{tabular}

Note: In computation of mortality and treatment success, participants with missing treatment outcome $(n=136)$ were excluded 
Table 3 Factors associated with treatment success among persons with BC-PTB in eastern Uganda

\begin{tabular}{|c|c|c|c|c|c|c|c|}
\hline \multirow{3}{*}{$\begin{array}{l}\text { Characteristics } \\
\text { Participants }\end{array}$} & \multirow[t]{3}{*}{ Level } & \multicolumn{2}{|c|}{ Tuberculosis treatment outcome } & \multicolumn{4}{|c|}{ Modified Poisson regression analysis } \\
\hline & & \multirow{2}{*}{$\begin{array}{l}\begin{array}{l}\text { Unsuccessful } \\
\text { (No. (\%)) }\end{array} \\
187(18.9)\end{array}$} & \multirow{2}{*}{$\begin{array}{l}\begin{array}{l}\text { Successful } \\
(\text { No. }(\%))\end{array} \\
800(81.1)\end{array}$} & \multicolumn{2}{|c|}{ Unadjusted analysis } & \multicolumn{2}{|c|}{ Adjusted analysis } \\
\hline & & & & $\mathrm{RR}$ & $95 \% \mathrm{Cl}$ & $\mathrm{aRR}$ & $95 \% \mathrm{Cl}$ \\
\hline \multirow[t]{4}{*}{ District } & Soroti & $104(55.6)$ & $359(44.9)$ & Ref & & Ref & \\
\hline & Kumi & $49(26.2)$ & $179(22.4)$ & 1.01 & $(0.93,1.10)$ & 1.02 & $(0.94,1.11)$ \\
\hline & Ngora & $26(13.9)$ & $115(14.4)$ & 1.05 & $(0.96,1.15)$ & 1.04 & $(0.95,1.14)$ \\
\hline & Serere & $8(4.3)$ & $147(18.4)$ & $1.22^{* * *}$ & $(1.15,1.30)$ & $1.22^{* * *}$ & $(1.14,1.30)$ \\
\hline \multirow[t]{2}{*}{ Sex } & Female & $46(24.6)$ & $290(36.2)$ & 1 & & 1 & \\
\hline & Male & $141(75.4)$ & $510(63.7)$ & $0.91^{* *}$ & $(0.86,0.96)$ & $0.92^{* *}$ & $(0.87,0.98)$ \\
\hline \multirow[t]{3}{*}{ Age group } & $15-34$ & $73(39.0)$ & $387(48.4)$ & 1 & & 1 & \\
\hline & $35-50$ & $66(35.3)$ & $262(32.8)$ & 0.98 & $(0.92,1.05)$ & 0.97 & $(0.91,1.04)$ \\
\hline & More than 50 & $48(25.7)$ & $151(18.9)$ & $0.88^{* *}$ & $(0.81,0.97)$ & $0.89^{* *}$ & $(0.81,0.97)$ \\
\hline \multirow[t]{2}{*}{ Persons with BC-PTB } & New & $154(82.4)$ & $708(88.5)$ & 1 & & 1 & \\
\hline & Previously treated & $33(17.6)$ & $92(11.5)$ & $0.90^{*}$ & $(0.80,1.00)$ & 0.94 & $(0.84,1.05)$ \\
\hline \multirow[t]{2}{*}{ HIV status } & Negative & $111(60.0)$ & $583(73.6)$ & 1 & & 1 & \\
\hline & Positive & $74(40.0)$ & $209(26.4)$ & $0.88^{* *}$ & $(0.81,0.95)$ & $0.88^{* *}$ & $(0.82,0.95)$ \\
\hline
\end{tabular}

Note: $95 \%$ confidence intervals for risk ratio (RR) in brackets; ${ }^{*} p<0.05,{ }^{* *} p<0.01,{ }^{* * *} p<0.001$; RR: Unadjusted risk ratio; aRR: Adjusted risk ratio

community-based DOTS than facility-based DOTS (RR, 0.38; 95\% CI, 0.20-0.71). However, mortality was more likely to occur when treatment of tuberculosis was given at a Referral Hospital compared to a Health Center IV level (RR, 1.96; 95\% CI, 1.19-3.24), when persons with BC-PTB were older than 50 years of age compared to 15 to 34 years (RR, 2.50; 95\% CI, 1.47-4.25), and when persons with BC-PTB were HIV infected compared to HIV non-infected (RR, 4.01; 95\% CI, 2.62-6.15). In adjusted analysis, mortality was lower when tuberculosis treatment was initiated in the years after 2015 , with a $20 \%$ reduction for every 1 year lapse from 2015 up to 2018 when the last data were retrieved $(\mathrm{aRR}, 0.80 ; 95 \% \mathrm{CI}$, 0.66-0.97). Delivery of tuberculosis treatment under community-based DOTS was protective of mortality (aRR, 0.26; 95\% CI, 0.13-0.50). But mortality rate was higher among persons with BC-PTB aged 50 years and older (aRR, 2.93; 95\% CI, 1.74-4.92) and those who were HIV infected (aRR, 4.48; 95\% CI, 2.95-6.79).

\section{Discussion}

Our data from rural eastern Uganda shows that treatment success rate for persons with BC-PTB is suboptimal and mortality rate is high. Our data also shows that HIV infection and older age are associated with reduced treatment success rate and increased mortality rate while CB-DOTS is associated with reduced mortality compared to facility-based DOTS. The treatment success rate reported here is no different from that reported in a recent meta-analysis of tuberculosis treatment success rate for sub Saharan Africa, which was 76.2\% [6]. Since the treatment success rate in eastern Uganda falls below the desired target of at least $90 \%$, site-specific measures are needed to address barriers to achieving high treatment success rate.

Mortality rate was high in this cohort of adult persons with BC-PTB. We were not able to ascertain the exact date of death from the records, therefore it is not clear whether mortality occurred early or later during treatment. The mortality rate in this study is comparable to that observed in other cohorts of persons with tuberculosis in sub Saharan Africa such as Ethiopia [11]. However, some cohorts from sub Saharan Africa have reported significantly lower mortality rates of less than $5 \%[12,13]$. It is clear that a wide variation in mortality rates in the treatment cohorts in sub Saharan Africa exists. These differences may be explained by the prevalence of HIV in the different countries across the continent, especially given the relationship between HIV and mortality [14] and that we found in our cohort.

Our study shows HIV infected persons with BC-PTB have reduced treatment success rate and increased mortality rate. These findings are not unique because the relationship between HIV and tuberculosis is wellestablished [15]. HIV is a known strong risk factor for tuberculosis disease, alters the clinical presentation, progression, and prognosis of tuberculosis as well as response to treatment [14]. In addition, tuberculosis disease is the commonest opportunistic infection among PLHIV, and the leading cause of mortality [7]. Dual treatment of tuberculosis and HIV is associated with increased pill burden and this may lead to medication fatigue and potentially non-adherence [16, 17]. Nonadherence to anti-tuberculosis medications in turn 
Table 4 Baseline characteristics of participants by survival status in eastern Uganda

\begin{tabular}{|c|c|c|c|c|}
\hline Characteristics & Level & $\begin{array}{l}\text { Alive } \\
n=906(91.8 \%)\end{array}$ & $\begin{array}{l}\text { Died } \\
n=81 \text { (8.2\%) }\end{array}$ & $p$-value \\
\hline \multirow[t]{4}{*}{ District } & Soroti & $418(46.1)$ & $45(55.6)$ & 0.027 \\
\hline & Kumi & $213(23.5)$ & $15(18.5)$ & \\
\hline & Ngora & $125(13.8)$ & $16(19.8)$ & \\
\hline & Serere & $150(16.6)$ & $5(6.2)$ & \\
\hline \multirow[t]{3}{*}{ Level of health facility } & Health Center IV & $386(42.6)$ & $22(27.2)$ & 0.023 \\
\hline & District Hospital & $182(20.1)$ & $19(23.5)$ & \\
\hline & Referral Hospital & $338(37.3)$ & $40(49.4)$ & \\
\hline \multirow[t]{2}{*}{ Location of health facility } & Rural & $252(27.8)$ & $23(28.4)$ & 1.000 \\
\hline & Peri-urban & $654(72.2)$ & $58(71.6)$ & \\
\hline \multirow[t]{2}{*}{ Health facility ownership } & Public & $808(89.2)$ & $72(88.9)$ & 1.000 \\
\hline & Private not for profit & $98(10.8)$ & $9(11.1)$ & \\
\hline \multirow[t]{4}{*}{ Year of TB treatment } & 2015 & $332(36.6)$ & $35(43.2)$ & 0.022 \\
\hline & 2016 & $192(21.2)$ & $25(30.9)$ & \\
\hline & 2017 & $209(23.1)$ & $14(17.3)$ & \\
\hline & 2018 & $173(19.1)$ & $7(8.6)$ & \\
\hline \multirow[t]{4}{*}{ Age category (years) } & $15-34$ & $436(48.1)$ & $24(29.6)$ & 0.002 \\
\hline & $35-50$ & $297(32.8)$ & $31(38.3)$ & \\
\hline & $>50$ & $173(19.1)$ & $26(32.1)$ & \\
\hline & Mean (SD) & $37.95(15.05)$ & $44.80(16.82)$ & $<0.001$ \\
\hline \multirow[t]{2}{*}{ Sex } & Male & $593(65.5)$ & $58(71.6)$ & 0.319 \\
\hline & Female & $313(34.5)$ & $23(28.4)$ & \\
\hline \multirow[t]{2}{*}{ Persons with BC-PTB } & New & $792(87.4)$ & $70(86.4)$ & 0.933 \\
\hline & Previously treated & $114(12.6)$ & $11(13.6)$ & \\
\hline \multirow[t]{2}{*}{ Transfer in } & No & $830(91.6)$ & $73(90.1)$ & 0.801 \\
\hline & Yes & $76(8.4)$ & $8(9.9)$ & \\
\hline \multirow[t]{4}{*}{ Pre-therapy MTB load } & $1+$ & $130(14.3)$ & $12(14.8)$ & 0.948 \\
\hline & $2+$ & $238(26.3)$ & $20(24.7)$ & \\
\hline & $3+$ & $287(31.7)$ & $28(34.6)$ & \\
\hline & GeneXpert & $251(27.7)$ & $21(25.9)$ & \\
\hline \multirow[t]{3}{*}{ Drug regimen } & 2RHZE/4RH & $560(61.8)$ & $41(50.6)$ & 0.136 \\
\hline & 2RHZE/6HE & $280(30.9)$ & $33(40.7)$ & \\
\hline & 2RHZES/1RHZE/5RHE & $66(7.3)$ & 7 (8.6) & \\
\hline \multirow[t]{2}{*}{ HIV status } & Negative & $673(74.3)$ & $31(38.3)$ & $<0.001$ \\
\hline & Positive & $233(27.7)$ & $50(61.7)$ & \\
\hline \multirow[t]{2}{*}{ Type of Directly Observed Therapy Short Course } & Health facility & $36(4.0)$ & $9(11.1)$ & 0.008 \\
\hline & Community & $870(96.0)$ & $72(88.9)$ & \\
\hline \multirow[t]{2}{*}{ Treatment support availability } & No & $111(12.3)$ & $11(13.6)$ & 0.864 \\
\hline & Yes & $795(87.7)$ & $70(86.4)$ & \\
\hline
\end{tabular}

Note: 1) 2RHZE/4RH: 2 months of Rifampicin (R), Isoniazid (H), Pyrazinamide (Z),Ethambutol / 4 months of RH; 2) 2RHZE/6EH: 2 months of RHZE)/ 6 months of EH; 3 ) 2RHZES/IRHZE/5RHE: 2 months of RHZE, Streptomycin/One month of RHZE/ 5 months of RHE; 4) MTB: Mycobacterium tuberculosis

reduce treatment success rate [18] and increase mortality rate [19]. In general, several pathways could explain the observed relationship. Our finding is consistent with several studies in sub Saharan Africa [20-28] where HIV infected persons have been documented to have reduced treatment success rate compared to HIV uninfected persons. HIV infected persons with BC-PTB might hence benefit from closer clinical and laboratory monitoring 
Table 5 Factors associated with mortality among persons with BC-PTB in rural eastern Uganda

\begin{tabular}{|c|c|c|c|c|c|c|c|}
\hline \multirow[t]{2}{*}{ Characteristics } & \multirow[t]{2}{*}{ Level } & \multirow{2}{*}{$\begin{array}{l}\text { Alive } \\
\boldsymbol{n}=906 \\
(91.8 \%)\end{array}$} & \multirow{2}{*}{$\begin{array}{l}\text { Died } \\
\boldsymbol{n}=81 \\
(8.2 \%)\end{array}$} & \multicolumn{4}{|c|}{ Modified Poisson regression analysis } \\
\hline & & & & \multicolumn{2}{|c|}{$\begin{array}{l}\text { Unadjusted analysis } \\
\text { (RR, } 95 \% \mathrm{Cl})\end{array}$} & \multicolumn{2}{|c|}{$\begin{array}{l}\text { Adjusted analysis } \\
\text { (RR, 95\% Cl) }\end{array}$} \\
\hline \multirow[t]{4}{*}{ District } & Soroti & $418(46.1)$ & $45(55.6)$ & Ref & & Ref & \\
\hline & Kumi & $213(23.5)$ & $15(18.5)$ & 0.68 & $(0.39,1.19)$ & 0.74 & $(0.25,2.18)$ \\
\hline & Ngora & $125(13.8)$ & $16(19.8)$ & 1.17 & $(0.68,2.00)$ & 1.74 & $(0.63,4.82)$ \\
\hline & Serere & $150(16.6)$ & $5(6.2)$ & $0.33^{*}$ & $(0.13,0.82)$ & 0.57 & $(0.18,1.88)$ \\
\hline \multirow[t]{3}{*}{ Level of health facility } & Health Center IV & $386(42.6)$ & $22(27.2)$ & Ref & & Ref & \\
\hline & District Hospital & $182(20.1)$ & $19(23.5)$ & 1.75 & $(0.97,3.16)$ & 1.38 & $(0.69,2.75)$ \\
\hline & Referral Hospital & $338(37.3)$ & $40(49.4)$ & $1.96^{* *}$ & $(1.19,3.24)$ & 1.99 & $(0.81,4.89)$ \\
\hline \multirow[t]{2}{*}{ Year of TB treatment } & 2015 & & & Ref & & Ref & \\
\hline & One year increase & & & $0.78^{* *}$ & $(0.64,0.93)$ & $0.80^{*}$ & $(0.66,0.97)$ \\
\hline \multirow[t]{3}{*}{ Age group } & $15-34$ & $436(48.1)$ & $24(29.6)$ & Ref & & Ref & \\
\hline & $35-50$ & $297(32.8)$ & $31(38.3)$ & $1.81^{*}$ & $(1.08,3.03)$ & 1.56 & $(0.96,2.55)$ \\
\hline & $>50$ & $173(19.1)$ & $26(32.1)$ & $2.50^{* * *}$ & $(1.47,4.25)$ & $2.93^{* * *}$ & $(1.74,4.92)$ \\
\hline \multirow[t]{2}{*}{ HIV status } & Negative & $673(74.3)$ & $31(38.3)$ & Ref & & Ref & \\
\hline & Positive & $233(27.7)$ & $50(61.7)$ & $4.01^{* * *}$ & $(2.62,6.15)$ & $4.48^{* * *}$ & $(2.95,6.79)$ \\
\hline \multirow[t]{2}{*}{ Type of DOTS } & Facility & $36(4.0)$ & $9(11.1)$ & Ref & & Ref & \\
\hline & Community & $870(96.0)$ & 72 (88.9) & $0.38^{* *}$ & $(0.20,0.71)$ & $0.26^{* * *}$ & $(0.13,0.50)$ \\
\hline
\end{tabular}

Note: $95 \%$ confidence intervals for risk ratio (RR) in brackets; ${ }^{*} p<0.05,{ }^{* *} p<0.01,{ }^{* * *} p<0.001$; RR: Unadjusted risk ratio; aRR: Adjusted risk ratio

and treatment adherence support so as to improve treatment success rate and reduce mortality rate.

In practice, strengthening the collaboration between tuberculosis and HIV control programs would improve the management of HIV infected persons with tuberculosis. This might enhance treatment success rate and reduced mortality rate.

We found that persons with BC-PTB who were more than 50 years of age had reduced treatment success rate and increased mortality rate. Studies in several parts of sub Saharan [20, 22, 23, 25, 27, 29-33], indicate that older or increasing age is associated with reduced treatment success rate among persons with tuberculosis. This could be because older persons interrupt treatment adherence more often than younger persons, are challenged by several health determinants such as low socio-economic status as well as low immunity that cannot effectively fight infections [25], and medical complications that comes along with ageing. Comparable to our findings, a systematic review [34] found that persons who are 30 years of age and beyond tend to be nonadherent to anti-tuberculosis medications. Older persons with tuberculosis might therefore benefit from close monitoring for response to tuberculosis treatment [35].

Our study indicates that male sex is associated with lower treatment success rate compared to female sex. This finding is consistent with several studies in Africa $[22,25,27]$. In particular, the study in Nigeria [27], reports gender disparities in treatment outcomes where male sex was associated with reduced sputum smear conversion at 2 and 5 months of treatment, increased treatment failure and reduced treatment success rate. Another study in Benin reports male sex is associated with increased treatment failure [36], and treatment failure translates into unsuccessful treatment of tuberculosis.

The observed difference could be attributed to men's poor healthcare seeking behavior compared to women [37], which translates to delayed diagnosis of tuberculosis and missing of clinic visits for drug refills hence treatment non-adherence and ultimately unsuccessful treatment of tuberculosis. Our finding implies that the need to design gender-specific interventions across tuberculosis programs might be beneficial.

Our data shows lower mortality rate in recent years, between 2016 and 2018, compared to later year. This improvement may be attributable to improvements in healthcare system over time: better staffing and improved healthcare provider competence and confidence to manage persons with $\mathrm{BC}$-PTB through mentorships and coaching, and better counseling among others. Elsewhere [38], healthcare providers indicated that tuberculosis clinics have been established across most health facilities to provide more time to understand and solve the challenges of persons with tuberculosis. This approach has led to better management of persons with tuberculosis. In addition, continuous quality improvement interventions have been introduced to tackle operational 
challenges in tuberculosis programing. It was stated that these initiatives have strengthened the healthcare system.

Our study indicates that community-based DOTS is associated with reduced mortality rate compared to facility-based DOTS. This finding is consistent with the results of previous systematic reviews and meta-analyses where community-based DOTS is reported to improve treatment completion and cure, and to reduce mortality rate [39-42]. One of the plausible reasons is that in community-based DOTS, persons with tuberculosis take medications under the direct supervision of a treatment supporter at home or in their community [43], and this is likely to result into better treatment adherence [44] and completion hence better cure rate and reduced mortality rate.

Our result is also consistent with findings of another meta-analysis which reports community-based DOTS is associated with lower mortality rate compared to facility-based DOTS [45]. Although there is sufficient evidence that community-based DOTS has better treatment outcomes compared to facility-based DOTS [39, 40], our result may suffer confounding due to indication, especially since we did not have data on disease severity. We recommend that in future, studies should measure disease severity when comparing mortality between facility and community-based DOTS.

\section{Study strengths and limitations}

Our study has several strengths. First, our sample size was large. Second, our study is the first in eastern Uganda. It has therefore set the benchmark for further studies in the same locality. Third, all the treatment outcomes were verified and this ensured data analyzed were accurate. However, there are some limitations that should be considered. This study was conducted in a rural setting. The findings may not apply to an urban setting due to variations in socio-economic status and structural challenges associated with rural dwelling such as longer distances to health facilities. Also, our results do not apply to persons with tuberculosis below 15 years of age and those with other forms of tuberculosis. Lastly, our data spanned a period of 3 years, which might not be sufficient to demonstrate long term trends in treatment success and mortality rates.

\section{Conclusions}

In conclusion, we have shown that adult persons with BC-PTB in rural eastern Uganda have suboptimal treatment success rate and high mortality rate. Tuberculosis and HIV co-infection and older age were associated with reduced treatment success and increased mortality rates.

Integration of tuberculosis and HIV prevention and management should be enhanced; particularly early screening and prophylaxis for tuberculosis among HIV infected persons, especially those who are older as they have poorer prognosis with TB disease. Communitybased DOTS should be implemented widely and more research should be done to examine successful ways for implementation of Community-based DOTS especially in rural areas such as those where our study was conducted.

\section{Abbreviations \\ aRR: Adjusted risk ratio; BC-PTB: Bacteriologically confirmed pulmonary tuberculosis; DOTS: Directly observed therapy short course; HIV: Human immunodeficiency virus; URR: Unadjusted risk ratio; WHO: World Health Organization}

\section{Acknowledgements}

We are grateful to the German Academic Exchange Services (DAAD) for awarding the primary author a doctoral studies scholarship at Mbarara University of Science and Technology, Uganda. We thank the District Health Officers of Soroti, Kumi, Serere, and Ngora districts for granting administrative clearance to collect data at respective study sites. We appreciate the support given by the District Tuberculosis and Leprosy Supervisors of Serere, Soroti, Kumi, and Ngora districts, the Tuberculosis focal persons of respective study sites and the Research Assistants.

\section{Authors' contributions}

$J I$, IKT, and FB conceptualized and designed the study. Jl obtained the data. $J$ I, IKT and FB analyzed the data and interpreted the results. JI, IKT, and FB drafted the manuscript. IKT and FB performed critical revisions of the manuscript. Jl, IKT, and FB all approved the final manuscript.

\section{Funding}

None.

Availability of data and materials

The dataset used/or analyzed during the current study are available from the corresponding author on reasonable request.

\section{Ethics approval and consent to participate}

This study was approved by Mbarara University of Science and Technology Research Ethics Committee Reference number 03/11-18) and the Uganda National Council for Science and Technology (Reference number HS 2531). The need for patient consent was waived by the ethics committee because data collection involved retrieval of records from large numbers of persons with tuberculosis, for whom it would have been logistically impractical to reach and seek individual consent.

Consent for publication

Not applicable.

\section{Competing interests}

The authors declare that they have no competing interests.

Received: 11 December 2019 Accepted: 2 April 2020

Published online: 15 April 2020

\section{References}

1. World Health Organization. Global Tuberculosis Report 2019. Geneva; 2019.

2. World Health Organization. Treatment of tuberculosis: guidelines for nationl programmes: World Health Organization; 2003.

3. British HIV Association (BHIVA). Aims of TB treatment London: BHIVA; 2019 [cited 201923 January ]. Available from: https://www.bhiva.org/2 OAimsofTBtreatment.

4. Stop TB Partnership. 90 (90) 90 the tuberculosis report for heads of state and governments. Geneva; 2017. p. 2017.

5. World Health Organization. Global Tuberculosis report 2018. Geneva; 2018

6. Izudi J, Semakula D, Sennono R, Tamwesigire IK, Bajunirwe F. Treatment success rate among adult patients with tuberculosis in sub-Saharan Africa: a systematic review and meta-analysis. BMJ Open 2019;9:e029400. 
7. World Health Organization. Global Tuberculosis Report. Geneva. Switzerland. 2017;2017.

8. World Health Organization (WHO). Treatment of tuberculosis: guidelines for national programmes. Geneva; 2003.

9. Schmidt OC, Kohlmann T. When to use the odds ratio or the relative risk? Int J Public Health. 2008:53:165-7.

10. $R$ Core Team. R: A language and environment for statistical computing. $R$ Foundation for Statistical Computing Vienna, 2018 [cited 2019]. Available from: https://www.R-project.org/.

11. Beyene Y, Geresu B, Mulu A. Mortality among tuberculosis patients under DOTS programme: a historical cohort study. BMC Public Health. 2016;16(1):883.

12. Datiko D, Lindtjørn B. Mortality in successfully treated tuberculosis patients in southern Ethiopia: retrospective follow-up study. Int J Tuberc Lung Dis. 2010;14(7):866-71.

13. Getahun B, Ameni G, Biadgilign S, Medhin G. Mortality and associated risk factors in a cohort of tuberculosis patients treated under DOTS programme in Addis Ababa, Ethiopia. BMC Infect Dis. 2011;11(1):127.

14. Maher D, Harries A, Getahun H. Tuberculosis and HIV interaction in subSaharan Africa: impact on patients and programmes; implications for policies. Trop Med Int Health. 2005;10(8):734-42.

15. Ungvarski PJ, Flaskerud JH. HIV/AIDS: a guide to primary care management: WB Saunders Comp; 1999.

16. Gebremariam MK, Bjune GA, Frich JC. Barriers and facilitators of adherence to TB treatment in patients on concomitant TB and HIV treatment: a qualitative study. BMC Public Health. 2010;10(1):651.

17. Boru CG, Shimels T, Bilal Al. Factors contributing to non-adherence with treatment among TB patients in Sodo Woreda, Gurage zone, southern Ethiopia: a qualitative study. J Infect Public Health. 2017;10(5):527-33.

18. Jones-Lopez EC, Ayakaka I, Levin J, Reilly N, Mumbowa F, Dryden-Peterson $S$, et al. Effectiveness of the standard WHO recommended retreatment regimen (category II) for tuberculosis in Kampala, Uganda: a prospective cohort study. PLoS Med. 2011;8(3):e1000427.

19. Zerbini EV, Greco A, Estrada S, Cisneros M, Colombo C, Beltrame S, et al. Risk factors associated with tuberculosis mortality in adults in six provinces of Argentina. Medicina. 2017;77(4):267-73.

20. Asres A, Jerene D, Deressa W. Tuberculosis treatment outcomes of six and eight month treatment regimens in districts of southwestern Ethiopia: a comparative cross-sectional study. BMC Infect Dis. 2016;16(1):653.

21. Gebrezgabiher G, Romha G, Ejeta E, Asebe G, Zemene E, Ameni G Treatment outcome of tuberculosis patients under directly observed treatment short course and factors affecting outcome in southern Ethiopia: a five-year retrospective study. PLoS One. 2016;11(2):e0150560.

22. Zenebe T, Tefera E. Tuberculosis treatment outcome and associated factors among smear-positive pulmonary tuberculosis patients in Afar, eastern Ethiopia: a retrospective study. Braz J Infect Dis. 2016;20(6):635-6.

23. Abebe T, Angamo MT. Treatment outcomes and associated factors among tuberculosis patients in Southwest Ethiopia. Greatment Outcom. 2015;57(4): 397-407.

24. Amante TD, Ahemed TA. Risk factors for unsuccessful tuberculosis treatment outcome (failure, default and death) in public health institutions, eastern Ethiopia. Pan Afr Med J. 2015;20:247.

25. Gabida M, Tshimanga M, Chemhuru M, Gombe N, Bangure D. Trends for tuberculosis treatment outcomes, new sputum smear positive patients in Kwekwe District, Zimbabwe, 2007-2011: a cohort analysis. J Tuberc Res. 2015;3(04):126

26. Dovonou A, Kpangon A, Amidou S, Dansou S, Attinssounon C, Keke R, et al. Risk factors for pulmonary tuberculosis treatment failure in rural settings in Benin, West Africa: a cohort study. Afr J Resp Med. 2017;12:2.

27. Oshi S, Alobu I, Ukwaja K, Oshi D. Investigating gender disparities in the profile and treatment outcomes of tuberculosis in Ebonyi state, Nigeria. Epidemiol Infect. 2015;143(5):932-42.

28. García-Basteiro LA, Respeito D, Augusto JO, López-Varela E, Sacoor C, Sequera GV, et al. Poor tuberculosis treatment outcomes in Southern Mozambique (2011-2012). BMC Infect Dis. 2016;16:214.

29. Berhe G, Enquselassie F, Aseffa A. Treatment outcome of smear-positive pulmonary tuberculosis patients in Tigray region, northern Ethiopia. BMC Public Health. 2012;12(1):537.

30. Ukwaja K, Oshi S, Alobu I, Oshi D. Six-vs. eight-month anti-tuberculosis regimen for pulmonary tuberculosis under programme conditions. Int J Tuberc Lung Dis. 2015;19(3):295-301.
31. Hassan A, Olukolade R, Ogbuji Q, Onyemocho A, Okwuonye L, Igbabul S-A, et al. Evaluation of tuberculosis treatment outcome of TB/HIV co-infection: a four-year retrospective cohort study in hiv-prevalent setting of North Central Nigeria. J Tuberc Res. 2016:4(03):122.

32. de Faria Gomes NM, Bastos MCdM, Marins RM, Barbosa AA, et al. Differences between risk factors associated with tuberculosis treatment abandonment and mortality. Pulmonary Med. 2015;2015:8.

33. Horne DJ, Hubbard R, Narita M, Exarchos A, Park DR, Goss CH. Factors associated with mortality in patients with tuberculosis. BMC Infect Dis. 2010; 10(1):258

34. Tola HH, Tol A, Shojaeizadeh D, Garmaroudi G. Tuberculosis treatment non-adherence and lost to follow up among TB patients with or without HIV in developing countries: a systematic review. Iran J Public Health. 2015;44(1):1-11.

35. Disassa H, Teklu T, Tafess K, Asebe G, Ameni G. Treatment outcome of tuberculosis patients under directly observed treatment of short course in Benishangul Gumuz region, Western Ethiopia: a ten-year retrospective study. Gen Med Open Access. 2015;2015.

36. Dovonou A, Kpangon A, Amidou S, Dansou S, Attinssounon C, Keke R, et al. Risk factors for pulmonary tuberculosis treatment failure in rural settings in Benin, West Africa: a cohort study. Knowledge, attitudes, and practice survey about antimicrobial resistance and prescribing among physicians in a hospital setting in Nairobi, Kenya Risk factors for pulmonary tuberculosis treatment failure in rural settings in Benin, West Africa: A cohort study 2017:8.

37. Republic of Uganda. The Uganda National Population Based Tuberculosis Prevalence Survey 2014-2016: summary findings and recommendations. Kampla; 2017.

38. Izudi J, Tamwesigire IK, Bajunirwe F. Explaining the successes and failures of tuberculosis treatment programs; a tale of two regions in rural eastern Uganda. BMC Health Serv Res. 2019;19(1):1-10

39. Wright J, Walley J, Philip A, Pushpananthan S, Dlamini E, Newell J, et al. Direct observation of treatment for tuberculosis: a randomized controlled trial of community health workers versus family members. Tropical Med Int Health. 2004;9(5):559-65.

40. Zhang H, Ehiri J, Yang H, Tang S, Li Y. Impact of community-based DOT on tuberculosis treatment outcomes: a systematic review and meta-analysis. PLoS One. 2016;11(2):e0147744.

41. Wright CM, Westerkamp L, Korver S, Dobler CC. Community-based directly observed therapy (DOT) versus clinic DOT for tuberculosis: a systematic review and meta-analysis of comparative effectiveness. BMC Infect Dis. 2015; 15(1):210

42. Tian J-H, Lu Z, Bachmann M, Song F. Effectiveness of directly observed treatment of tuberculosis: a systematic review of controlled studies. Int J Tuberc Lung Dis. 2014;18(9):1092-8

43. World Health Organization. Treatment of Tuberculosis: guidelines for national programmes. Geneva; 2003.

44. Garner P, Smith H, Munro S, Volmink J. Promoting adherence to tuberculosis treatment. Bull World Health Organ. 2007;85:404-6.

45. Alipanah N, Jarlsberg L, Miller C, Linh NN, Falzon D, Jaramillo E, et al. Adherence interventions and outcomes of tuberculosis treatment: a systematic review and meta-analysis of trials and observational studies. PLOS Med. 2018;15(7):e1002595.

\section{Publisher's Note}

Springer Nature remains neutral with regard to jurisdictional claims in published maps and institutional affiliations.

\section{Ready to submit your research? Choose BMC and benefit from:}

- fast, convenient online submission

- thorough peer review by experienced researchers in your field

- rapid publication on acceptance

- support for research data, including large and complex data types

- gold Open Access which fosters wider collaboration and increased citations

- maximum visibility for your research: over $100 \mathrm{M}$ website views per year

At $\mathrm{BMC}$, research is always in progress.

Learn more biomedcentral.com/submission 